\title{
Online Instruction Special Issue: Introduction
}

\author{
SANDY MILLER, Guest Editor \\ Southern Methodist University \\ slmiller@cox.smu.edu \\ CHRISTINA SHELEY, Guest Editor \\ Cornell University \\ cms542@cornell.edu
}

Online instruction in business librarianship, whether through reference interactions, classes, workshops, research guides or tutorials, has been undergoing a major shift at learning institutions due to a variety of factors. These factors include such things as the rise of online degree programs, the increasing availability of digital tools to librarians, and most recently, the COVID-19 pandemic. The Online Instruction Special Issue showcases the creativity and flexibility of librarians in meeting the challenge of learning new ways to engage learners successfully in the virtual and hybrid environment.

The Teaching \& Learning column features an article by Nora B. Wood and Saira Raza (Emory University), "Cultivating Business Intelligence through Online Workshops," which details the process at Goizueta Business Library of the creation and implementation of the for-credit asynchronous Business Essentials course taught online via Canvas. It provides practical guidance for librarians interested in creating an online workshop program at their institutions.

The COVID-19 Impact section includes a collection of short essays detailing the recent effects of the pandemic on business reference and instruction and ways that librarians have responded by developing solutions to the disruption in traditional methods of engagement with students and faculty. Some essays address the use of teaching tools such as Microsoft Teams or Google Jamboard at different types of institutions, which provide unique contexts for successful implementation in solving specific problems. Other essays provide a view into developing new ways to deliver various types of instruction activities, such as orientations, research consultations, and experiential learning opportunities, under the constraints of the global pandemic.

Key takeaways from these timely articles provide ideas and inspiration for solving the unique challenges faced by instructors seeking to provide engaging and effective outreach and learning opportunities, whether that occurs in a virtual or hybrid environment. 